\title{
COLECCIÓN CORNEAL INTRAESTROMAL Y QUERATITIS POR FUSARIUM SPP: PRESENTACIÓN DE DOS CASOS Y REVISIÓN DE LA LITERATURA
}

\author{
Carlos Pérez Díaz ${ }^{1}$, Patricia Barrios Castañeda², José David Miranda Echavarría ${ }^{3}$, Juan Sebastián Bravo Oje- \\ DA ${ }^{4}$, Yesid FABIÁN MANTILLA FLóReZ4. \\ ${ }^{1} \mathrm{MD}$ Infectólogo. Hospital Militar Central. Jefe del servicio de Infectología, \\ ${ }^{2}$ TC MD Hospital Militar Central. Servicio de Oftalmología, \\ ${ }^{3}$ Residente de Segundo año, Oftalmología, \\ ${ }^{4} \mathrm{MD}$, Docente área de enfermedades infecciosas. Universidad Militar Nueva Granada.
}

Correspondencia: garik1617@hotmail.com

Recibido: Julio 9 de 2013 Aceptado: Octubre 2 de 2013

\begin{abstract}
Resumen
Las infecciones oculares por hongos filamentosos han aumentado su incidencia con el pasar de los años. Los traumas corneales, la terapia inmunosupresora y el uso de lentes de contacto han hecho que éstas aumenten su incidencia, pero existe un pequeño porcentaje de paciente que sin ningún factor de riesgo presentan infecciones por estos mohos. En este artículo reportamos dos casos de infección ocular por Fusarium spp. en dos pacientes de 21 y 30 años de edad respectivamente, inmunocompetentes, pertenecientes a las Fuerzas Militares y sin factores de riesgo asociados.
\end{abstract}

Palabras Clave: Queratitis fúngica, moho, Fusarium spp.

\section{COLLECTION INTRASTROMAL CORNEAL AND KERATITIS BY FUSARIUM SPP: REPORT OF TWO CASES AND REVIEW OF THE LITERATURE}

\begin{abstract}
The filamentous fungal eye infections have been increasing in incidence in the last years. Corneal trauma, immunosuppressive therapy and use of contact lenses have increased their incidence, nonetheless a small percentage of patients with no risk factors still present with these mold infections. In this article we report a case of ocular infection by Fusarium spp. in two patients, a 21-year-old and a 30-year-old males. They work with the Military Forces, and were immunocompetent with no risk factors associated to the problem.
\end{abstract}

Keywords: Fungal keratitis, mold, Fusarium spp. 


\title{
RECOLHA CORNEANO INTRA-ESTROMAL E CERATITE POR FUSARIUM SPP: RELATO DE DOIS CASOS E REVISÃO DA LITERATURA
}

\begin{abstract}
Resumo
As infecções oculares por fungos filamentosos têm aumentado a sua incidência com o passar dos anos. Os traumas da córnea, a terapia imunossupressora e o uso de lentes de contato têm feito que estas aumentem a sua incidência, mas existe uma pequena percentagem de pacientes que semnenhumfator de riscoapresentam infecções por estes bolores. Em este artigo reportamos dois casos de infecção ocular por Fusarium spp. em dois pacientes de 21 e 30 anos de idade respectivamente, imunocompetentes, pertencentes às Forças Militares e semfatores de risco associados.

Palavras Chave: Ceratitefúngica, bolor, Fusarium spp.
\end{abstract}

\section{Introducción}

Las infecciones oculares son la segunda causa de ceguera en el mundo superadas solo por las cataratas (1). Representan un gran problema de salud pública, requieren de un diagnóstico oportuno y un manejo temprano para evitar la ceguera permanente e incluso, en casos lamentables, la enucleación. Los principales factores de riesgo para desarrollar infecciones corneales son las abrasiones corneales (2), el uso de lentes de contacto (3), la conjuntivitis alérgica $(3,4)$, la medicación ocular contaminada, las inmunodeficiencias, la disfunción de la superficie lagrimal $(1,2)$, la disminución o alteración de las secreciones lagrimales (síndrome de Sjögren, quemaduras corneales etc) y las anomalías anatómicas, entre otras.

Las queratitis micóticas representan el $5-10 \%$ de las infecciones corneales (4) y su incidencia varía según la región geográfica, encontrándose reportes de hasta $37,6 \%$ en Ghana5 y $36 \%$ en Bangladesh (6). Sin embargo, la incidencia de estas entidades en Reino Unido y Norte América es baja.

Las especies de Fusarium continúan siendo la principal causa de queratitis fúngica en climas tropicales y subtropicales (7). La enfermedad se desencadena en pacientes competentes inmunológicamente y el uso de lentes de contacto ha sido reconocido como el factor de riesgo más importante para desarrollar esta enfermedad. Estudios realizados por Rosa y colaboradores en el sur de la Florida muestran que Fusarium oxysporum es el principal agente causal de queratitis fúngica (37\%) seguido de Fusarium solani (24\%), Candida spp (12,5\%) y algunas especies de Aspergillus (4\%) $(1,3)$.

En junio de 2006 el CDC confirmó un brote de queratitis por este hongo asociado al uso de una solución para lentes de contacto en 164 pacientes, de los cuales 55 requirieron de trasplante corneal $(7,10)$. Este ha sido el brote más importante de queratitis por Fusarium spp. jamás reportado.

\section{Caso Clínico 1}

Paciente masculino de 21 años de edad quien llega al Servicio de Urgencias, remitido de primer nivel por ingreso de cuerpo extraño (mosquito) en ojo izquierdo con posterior presentación de dolor ocular, lagrimeo, disminución de la agudeza visual y aparición de lesión blanquecina. El paciente consultó en hospital de primer nivel donde inician tratamiento antibiótico pero, por persistencia del cuadro clínico y progresión de la lesión ocular, deciden remitirlo a nuestra institución.

Al examen oftalmológico de ingreso a la institución, se encuentra agudeza visual sin corrección 20/20 en ojo derecho, 20/200 en ojo izquierdo (a 3 metros de distancia). Blefaroespasmo en ojo izquierdo, movimientos oculares bilaterales sin alteraciones. A la biomicroscopía en ojo izquierdo se observa hiperemia conjuntival en $360^{\circ}$, aumento del menisco lagrimal, edema corneal positivo con lesión ulcerativa paracentral inferior temporal de $4 \mathrm{~mm}$ de diámetro con colección intraestromal subyacente (figuras 1 y 2 ). 
Fundoscopia directa de ojo derecho normal, ojo izquierdo no valorable por opacidad de medios. Se decide hospitalizar al paciente con tratamiento antibiótico y se toma muestra de raspado corneal para estudios microbiológicos. El examen directo del raspado corneal evidencia hifas aseptadas, hialinas en escasa cantidad. Se cultiva la muestra en agar sangre y a las 72 horas se aprecia crecimiento de colonias algodonosas de color blanco con pigmento rosa (tabla 1), (figura 3). $\mathrm{Al}$ examen microscópico se observan hifas septadas, hialinas con ramificaciones escasas y microconidias compatibles con Fusarium spp (figura 4).

De acuerdo con los resultados obtenidos en la muestra se decide suspender antibiótico intravenoso y se inicia manejo con azoles en gotas oftálmicas, inyecciones subconjuntivales y por vía oral.

La evolución clínica del paciente fue favorable con el antimicótico instaurado observándose regresión de la lesión, disminución en la congestión conjuntival y recuperación gradual de la visión (20/100) al día $8^{\circ}$ de instaurado el tratamiento (figura 5).

Al día 20 de manejo se suspendió antimicótico subconjuntival y se ordenó continuar con el colirio oftálmico y las tabletas por vía oral. Para el día 22 el paciente asistió a control encontrándose lesión y erosión conjuntival con disminución estimada de tamaño del $40 \%$.

\section{Caso Clínico 2}

Al día 20 de manejo, se suspendió antimicótico subconjuntival y se ordenó continuar con el colirio oftálmico y las tabletas por vía oral. Para el día 22 el paciente asistió a control encontrándose lesión y erosión conjuntival con disminución estimada de tamaño del $40 \%$.

$\mathrm{Al}$ ingreso a la institución se observa en examen oftalmológico agudeza visual en ojo derecho, bultos a 1 metro de distancia que no corrige con pinhole. Ojo izquierdo agudeza visual 20/20. Blefaroespasmo derecho y edema bipalpebral. No hay restricciones en movimientos oculares externos. Pupilas centradas isocóricas reactivas a la luz. En la biomicroscopía bordes palpebrales regulares, secreción mucopurulenta escasa en fondo de saco, hiperemia conjuntival a $360^{\circ}$. En cornea se observa úlcera de aproximadamente $5 \times 6$ $\mathrm{mm}$ de bordes irregulares, centro sucio, infiltrados estromales y reacción inflamatoria endotelial que compromete el eje visual. Se decide hospitalizar al paciente con tratamiento antibiótico y antifúngico con Fluconazol (oral y colirio) para realización de estudios microbiológicos.

Se realiza raspado corneal con cureta fina y se cultiva en agar sangre y agar Sabouraud, este último a $25^{\circ} \mathrm{C}$. Ambos cultivos son positivos para colonias algodonosas blancas con pigmento color violeta en la base del agar.

Con el resultado obtenido en los exámenes microbiológicos se decide suspender antibióticos y por servicio tratante se inicia colirio de Natamicina al 5\%. Se hace interconsulta al servicio de infectología el cual sugiere toma de estudio de extensión (TAC cerebral simple), complementar esquema antifúngico con Posaconazol 7,5 cc vía oral cada 12 horas por seis semanas y adicionar Cefepime a 2 gr IV cada 12 horas el cual se suspende al completar 14 días. El paciente presenta evolución favorable con remisión progresiva de la colección corneal. Recupera agudeza visual de forma gradual hasta obtenerse AV-OD 20/200 a las 2 semanas de tratamiento. Hay disminución del dolor y remisión del edema bipalpebral, se da salida al paciente con tratamiento tópico y por vía oral además de seguimiento estricto ambulatorio.

\section{Discusión}

Las queratitis micóticas siguen siendo una causa importante morbilidad en nuestro medio (10). Los hongos no son capaces de atravesar el epitelio corneal intacto y para ello las alteraciones de la superficie corneal son el principal factor de riesgo que permite desarrollar estas enfermedades, así como lo son el uso de lentes de contacto, estos últimos por perpetuar la colonización microbiológica (2).

Es importante resaltar que en el caso de infecciones micóticas oculares, el uso de corticoides sistémicos o antibióticos de amplio espectro no representan un factor predisponente (11).

Como la mayoría de los hongos filamentosos, Fusarium spp. es un hongo de amplia distribución en la naturaleza, saprófito y patógeno facultativo de plantas que puede generar enfermedades de gran importancia en el ser humano por la producción de micotoxinas (12) y la invasión tisular generalizada en personas inmunosuprimidas, especialmente pacientes neutropénicos (13), con neoplasias hematológicas $(14,15)$ trasplantes de médula ósea u órganos sólidos (16). 
El proceso fisiopatológico comienza con el ingreso del moho al espacio corneal. Los traumas oculares favorecen la colonización micótica de la superficie, especialmente los traumas con plantas y vegetales. En caso de haber disrupción epitelial agregada, el hongo se incorpora al espacio subcorneal y allí prolifera sin la liberación de factores quimiotácticos, evitando así la respuesta inmune del hospedero. Sólo en infecciones oculares por Candida spp. se ha demostrado la producción de fosfolipasas y lipofosfolipasas que le permiten al hongo invadir con mayor facilidad el tejido (17). Por otro lado, los mohos se diseminan por contigüidad hasta llegar al estroma y la membrana de Descemet (18). Una vez allí y sin el efecto de la respuesta inmunológica, se perpetúa la infección.

Los síntomas generalmente aparecen después de 5 a 7 días del contacto con el objeto contaminante. Comúnmente se presenta sensación de cuerpo extraño, lagrimeo, inyección conjuntival generalizada, disminución de la agudeza visual, fosfenos y posteriormente la aparición de una lesión infiltrante en la superficie corneal con desepitelización (19).

Siempre que se sospeche una lesión de etiología infecciosa a nivel corneal se deben separar las muestras para realizar cultivos bacterianos y micóticos, estos últimos de gran importancia si existen antecedentes que hagan sospechar una queratitis fúngica (tabla 3) (20-22).

Hay dos formas por las cuales se puede confirmar el diagnóstico, los métodos microbiológicos y los métodos moleculares. Fusarium spp crece fácilmente en agar Sabouraud a $25^{\circ} \mathrm{C}$ donde produce colonias algodonosas de color blanco y con un característico color rosa-rojo en la base del agar. Eleinen y colaboradores encontraron que Fusarium spp. era el segundo hongo que con mayor frecuencia se aislaba de pacientes con queratitis fúngica $(15,4 \%)(23)$. Otros autores han encontrado que Fusarium spp. es el principal patógeno encontrado en las muestras oculares $(24,25,26)$.

La calidad de la muestra determina el éxito del aislamiento del patógeno en los estudios microbiológicos; tanto la profundidad como la cantidad de la muestra corneal deben ser representativas para así aumentar la carga microbiológica (27).

En microscopia óptica se observan micelios septados, hialinos que producen tres tipos diferentes de esporos: microconidias, macroconidias y clamidosporas. Algunas especies producen los tres tipos de esporos mientras que otras no. El tamaño y la forma de las conidias y la presencia o ausencia de vesículas lipídicas en el interior de los esporos constituyen una de las claves para la caracterización del género y las especies (28). Los métodos moleculares como la Reacción en Cadena de la Polimerasa (PCR), para la detección de ácidos nucleicos resulta práctica dada la rapidez con que se obtienen los resultados (29), pero este método diagnóstico no siempre esta disponible en todas las instituciones de salud. Algunos autores han establecido la sensibilidad de las pruebas moleculares entre un 70-97\% con una especificidad mayor al $98 \%$ (30).

Es importante resaltar que se han reportado casos de diseminación por contigüidad hacía tejidos profundos, aún en pacientes inmunocompetentes, por lo que se debe estudiar si existe compromiso de estructuras internas en cráneo a todo paciente con infecciones oculares por hongos filamentosos. Los factores de mal pronóstico los constituyen la demora en el diagnóstico, la profundidad de la lesión, el uso de corticoides tópicos (18), extensión a estructuras adyacentes en cráneo y la sobreinfección por otros patógenos (31).

Los antifúngicos más utilizados en las infecciones oculares por Fusarium spp son los polienos y los azoles.

La natamicina presenta un amplio espectro de actividad incluyendo mohos. Debido a su baja toxicidad, la natamicina se considera el tratamiento de elección para la queratitis fúngica pero, dada su baja distribución a cornea se usa en casos de infecciones superficiales (32). Los antifúngicos orales ketoconazol y fluconazol presentan altas concentraciones en cámara anterior y cornea por lo cual constituyen el tratamiento para infecciones complicadas $(1,17,32)$, la administración subconjuntival se debe usar en pacientes con queratitis severas o queratoesclerosis. El tratamiento efectivo requiere de aplicaciones tópicas de forma frecuente por largos períodos de tiempo (generalmente 12 semanas), solo en casos de infecciones complicadas se adiciones medicación sistémica. De no iniciarse el tratamiento de forma oportuna la infección puede progresar a una endoftalmitis (33). Se debe realizar seguimiento de la lesión y evaluar la respuesta al tratamiento. Signos clínicos de mejoría incluyen:

- Disminución del perímetro de la lesión.

- Reducción en el infiltrado estromal.

- Re-epitelización progresiva. 
El desbridamiento corneal resulta eficaz, ya que permite la eliminación de los microorganismos y favorece el ingreso de los antifúngicos tópicos. Debido a que en la mayoría de los casos, el tratamiento instaurado no resulta eficaz para erradicar completamente la infección, en última instancia se debe recurrir a la cirugía oftalmológica (34).

\section{Figura 1}

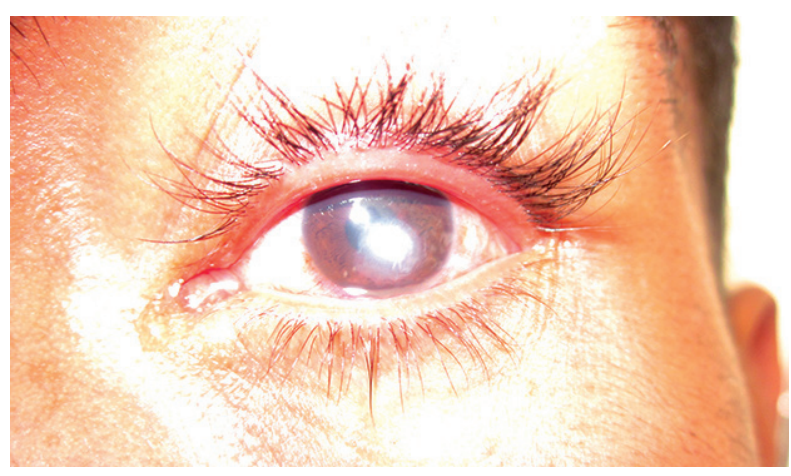

Figura 2

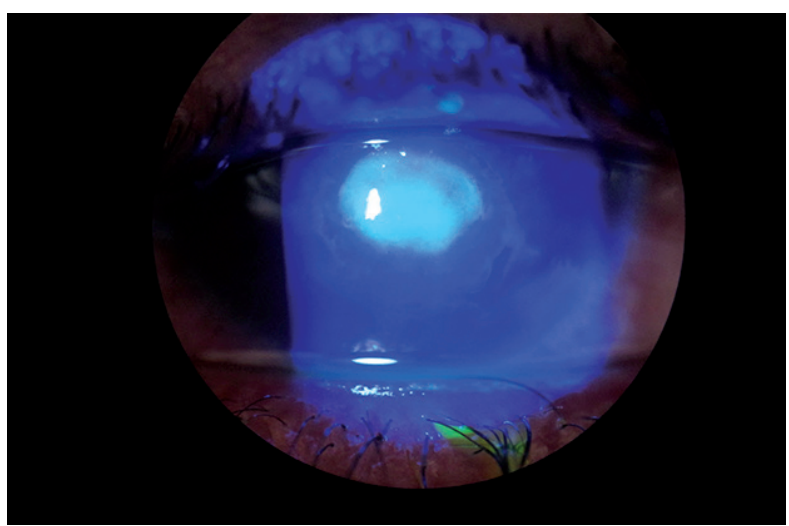

Figura 3. Cultivo en agar sangre de raspado corneal que muestra colonias miceliales densas con pigmento rosa-pardo correspondientes $a$ Fusarium spp.

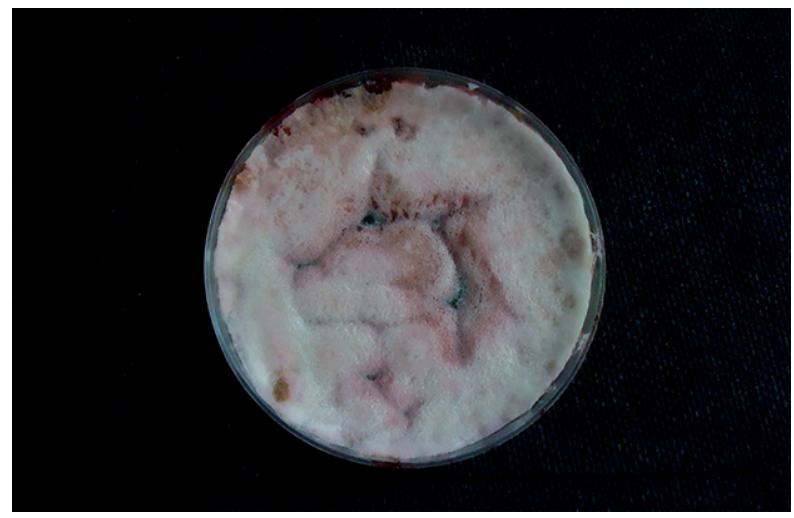

Figura 4. Cultivo de raspado corneal. Microscopia de luz. Azul de lactofenol 1000X. Se observan hifas septadas, ramificadas, hialinas con microconidias correspondientes a Fusarium spp.

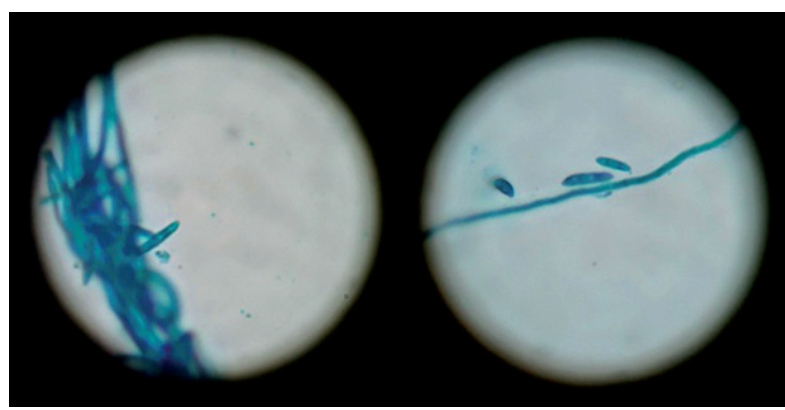

Figura 5.

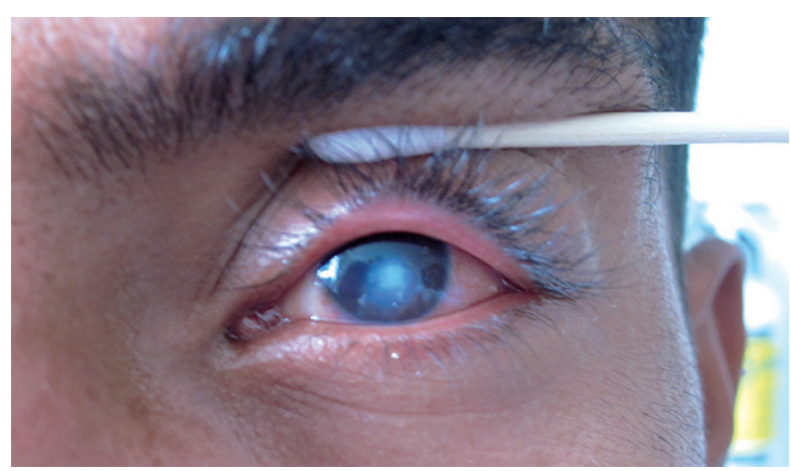

Tabla 1.

\begin{tabular}{|l|l|l|}
\hline \multicolumn{3}{|c|}{ Estudio microbiológico } \\
\hline $23 / 04 / 11$ & $\begin{array}{l}\text { Cultivo gérmenes } \\
\text { comunes }\end{array}$ & $\begin{array}{l}\text { Negativo. A las 72 horas } \\
\text { colonias miceliales. }\end{array}$ \\
\hline $26 / 04 / 11$ & Cultivo para hongos & $\begin{array}{l}\text { Positivo para Fusarium } \\
\text { spp. }\end{array}$ \\
\hline
\end{tabular}

Tabla 2.

\begin{tabular}{|l|l|l|}
\hline \multicolumn{3}{|c|}{ Estudio microbiológico } \\
\hline $21 / 11 / 11$ & $\begin{array}{l}\text { Cultivo gérmenes } \\
\text { comunes }\end{array}$ & $\begin{array}{l}\text { Número moderado de } \\
\text { restos de micelio. }\end{array}$ \\
\hline $03 / 12 / 11$ & Cultivo para hongos & $\begin{array}{l}\text { Positivo para Fusarium } \\
\text { sacchari. }\end{array}$ \\
\hline
\end{tabular}

Tabla 3.

\begin{tabular}{|l|}
\hline \multicolumn{1}{|c|}{ Factores de riesgo para queratitis fúngica } \\
\hline - Trauma ocular (especialmente vegetal). \\
\hline - Uso de corticoides tópicos. \\
\hline - Cirugía previa (queratoplastia, cataratas, cirugía láser in situ). \\
\hline - Queratitis crónica por virus herpes. \\
\hline - Hombres jóvenes sanos. \\
\hline - Ocupación en la agricultura. \\
\hline
\end{tabular}




\section{Carlos Pérez Díaz, Patricia Barrios Castañeda, José David Miranda Echavarría, Juan Sebastián Bravo OJeda, Yesid Fabián Mantilla Flórez}

\section{Referencias}

1. Srinivasan M. Fungal keratitis. Curr Opin Ophthalmol. 2004; 15: 321-7.

2. Rosa RH, Miller D, Alfonso E C. The changing spectrum of fungal keratitis in South Florida. Ophthalmology. 1994; 101: 1005-13.

3. Tanure MA, Cohen EJ, Sudesh S, Rapuano CJ, Laibson PR. Spectrum of fungal keratitis at Wills Eye Hospital, Philadelphia. Pennsylvania. Cornea. 2000; 19: 307-12.

4. Asbell P, Stenson S. Ulcerative keratitis: Survey of 30 years' laboratory experience. Arch Ophthalmol. 1982; 100: 77-80.

5. Dunlop A, Wright E, Howlader S et al. Suppurative corneal ulceration in Bangladesh: A study of 142 cases examining the microbiological diagnosis, clinical and epidemiological features of bacterial and fungal keratitis. Aust NZ J Ophthalmol. 1994; 22: $105-10$

6. Leck AK, Thomas PA, Hagan M, et al. Aetiology of suppurative corneal ulcers in Ghana and South India, and epidemiology of fungal keratitis. Br J Ophthalmol. 2002; 86: 1211-15.

7. Xie L, Zhai H, Zhao J, Sun S, Shi W, Dong X. Antifungal Susceptibility for Common Pathogens of Fungal Keratitis in Shandong Province, China. Am J Opthalmol. 2008; 146: 260-265.

8. Chang DC, Grant GV, O'Donell C, Wannemuehler KA, Noble-Wang J, Rao C. Multistate Outbreak of Fusarium Keratitis Associated With Use of a Contact Lens Solution. JAMA. 2006; 296(8): 953-63.

9. Centers for Disease Control and Prevention. Fusarium keratitisMultiple sates 2006. MMWR. 2006; 55: 400-1.

10. Sedo S, Iribarne Y, Fossas M, Vendrell C, Ortiz F. Queratitis Fúngica. Annals d'Oftalmologia. 2003; 11(3): 168-175.

11. David V Seal. Ocular infection. Ed. Martin Dunitz; 1998.

12. Booth C. The Genus Fusarium. Kew, Surrey: CMI.; 1971. pp. 19-31.

13. Lewis R, Hogan H, Howell A, Safdar A. Progressive fusariosis: unpredictable posaconazole bioavailability, and feasibility of recombinant interferon-gamma plus granulocyte macrophage-colony stimulating factor for refractory disseminated infection. Leuk Lymphoma. 2008; 49: 163-5.

14. Nucci M, Anaissie E. Fusarium infections in immunocompromised patients. ClinMicrobiol Rev. 2007; 20: 695-704.

15. Leventakos K, Lewis R, Kontoyiannis D P. Fungal Infections in Leukemia Patients: How Do We Prevent and Treat Them? CID. 2010; 50: 405-15.

16. Safdar A, Armstrong D. Infections in Patients With Hematologic Neoplasms and Hematopoietic Stem Cell Transplantation: Neutropenia, Humoral, and Splenic Defects. CID. 2011; 53(8): 798-806.

17. Matsumoto Y, Murat D, Kojima T, Shimazaki J, Tsubota K. The comparison of solitary topical micafungin or fluconazole application in the treatment of Candida fungal keratitis. $\mathrm{Br} J$ Ophthalmol. 2011; 95(10): 1406-9.
18. Vemuganti GK, Garg P, Gopinathan U, Naduvilath TJ, John RK, Buddi R, et al. Evaluation of agent and host factors in progression of mycotic keratitis. Ophthalmology. 2002; 109: 1538-46.

19. Thomas PA, Leck AK, Myatt M. Characteristic clinical features as an aid to the diagnosis of suppurative keratitis caused by filamentous fungi. Br J Ophthalmol. 2005; 89: 1554-8.

20. Garg P, Mahesh S, Bansal AK, Gopinathan U, Rao GN. Fungal infection in sutureless self-sealing incision for cataract surgery. Ophthalmol. 2003; 110(11): 2173-7.

21. Keyhani K, Seedor JA, Shah MK, Terraciano AJ, Ritterband DC. The incidence of fungal keratitis and endophthalmitis following penetrating keratoplasty. Cornea. 2005; 24(3): 288-91.

22. Thomas PA. Fungal infections of the cornea. Eye. 2003; 17(8): 852-62.

23. Eleinen KG, Mohalhal A, Elmekawy H, Abdulbaki A, Sherif AM, El-Sherif RH. Polymerase Chain Reaction-guided Diagnosis of Infective Keratitis - A Hospital-based Study. Current Eye Research. 2012; 37(11): 1005-11.

24. Embong Z, Wan Hitam WH, Yean CY, Abdul NH, Kamarudin B, Zainal SK. Specific detection of fungal pathogens by $18 \mathrm{~S} r \mathrm{rNA}$ gene PCR in microbial keratitis. BMC Ophthalmol. 2008; 8: 7.

25. Kim E, Chidambaram JD, Srinivasan M Lalitha P, Wee D, Lietman TM. Prospective comparison of microbial culture and polymerase chain reaction in the diagnosis of corneal ulcer. Am J Ophthalmol. 2008; 146: 714-23,723. e1.

26. Fitzsimons R, Peters AL. Miconazole and ketoconazole as a satisfactory first-line treatment for keratomycosis. Am J Ophthalmol. 1986; 101:605-8.

27. Ferrer C, Alió JL. Evaluation of molecular diagnosis in fungal keratitis. Ten years of experience. J Ophthalmic Inflamm Infect. 2011; 1: 15-22.

28. Franco L. Fusarium spp. En: Díaz F J, Estrada S, eds. Microbiología de las infecciones humanas. $1^{\text {st }}$ ed. Medellín: Colombia; 2007: 696-9.

29. Gaudio PA, Gopinathan U, Sangwan V. Polymerase chain reaction based detection of fungi in infected corneas. Br J Ophthalmol. 2002; 86: 755-60.

30. Vengayil S, Panda A, Satpathy G, Nayak N, Ghose S, Patanaik D. Polymerase chain reaction-guided diagnosis of mycotic keratitis: A prospective evaluation of its efficacy and limitations. Invest Ophthalmol Vis Sci. 2009; 50: 152-6.

31. Zloty P. Diagnosis and management of fungal keratitis. American Academy of Ophthalmology. Focal points. 2002; 20(6): 1-13.

32. Prajna NV, Nirmalan PK, Mahalakshmi R, Lalitha P, Srinivasan M. Concurrent use of $5 \%$ natamycin and $2 \%$ econazole for the management of fungal keratitis. Cornea. 2004; 23(8): 793-6.

33. Pflugfelder SC, Flynn HW, Zwickey TA, Forster RK, Tsiligianni A, Culberston W W, et al. Exogenous fungal endophthalmitis. Ophthalmol. 1988; 95: 19-30.

34. Dursun D, Fernández V, Miller D, Alfonso EC. Advanced Fusarium Keratitis Progressing to Endophthalmitis. Cornea. 2003; 22(4): 300-303. 